\title{
0 sistema postal brasileiro em transformação: propostas e mudanças na regulação do mercado e na reestruturação do modelo organizacional da Empresa Brasileira de Correios e Telégrafos (1994-2011)
}

\author{
Tadeu Gomes Teixeira \\ Universidade Federal do Maranhão
}

\begin{abstract}
Objetiva-se neste artigo responder a seguinte questão: quais foram as propostas e as mudanças nos mecanismos de regulação do mercado postal brasileiro e na estrutura organizacional da Empresa Brasileira de Correios e Telégrafos (ECT) entre 1994 e 2011 ? Verifica-se que, entre 1994 e 2002, a proposta do governo federal, apresentada em 1999 por meio da "Nova Lei postal", previa a criação do Sistema Nacional de Correios, liberalizando o mercado postal, criando um órgão regulador e transformando a ECT em uma empresa de economia mista. Apesar da não aprovação do projeto de lei, algumas de suas propostas foram retomadas, a partir de 2008, pelos diagnósticos e propostas do governo Lula para reestruturar o setor postal brasileiro. As propostas subsidiaram a aprovação da Lei no 12.490 de 2011, que internacionalizou a ECT, ampliou os segmentos de mercado da empresa e a reestruturou com base no modelo das sociedades anônimas.
\end{abstract}

Palavras-chave: correios; liberalização do mercado postal; regulação postal; reforma do modelo organizacional.

El sistema de correos de Brasil en transformación: las propuestas y los cambios en la regulación del mercado y la reestructuración del modelo de organización de la Empresa Brasileña de Correos y Telégrafos (1994-2011)

Objetivo de este artículo es responder a la siguiente pregunta: ¿cuáles son las propuestas y los cambios en los mecanismos de regulación del mercado postal de Brasil y de la estructura organizativa de la Empresa Brasileña de Correos y Telégrafos (ECT) entre 1994 y 2011? Se encontró que, entre 1994 y 2002, la propuesta del gobierno federal, presentado en 1999 por la "Nueva Ley de Correos", dispuso la creación del Sistema Nacional de Correos, la liberalización del mercado postal, la creación de un regulador y convirtiendo ECT en una sociedad de economía mixta. A pesar de la desaprobación del proyecto de ley, algunas de sus propuestas fueron tomadas, a partir de 2008, por los diagnósticos y

DOI: http://dx.doi.org/10.1590/0034-76121470

Artigo recebido em 13 fev. 2013 e aceito em 26 jun. 2014.

Rev. Adm. Pública - Rio de Janeiro 48(6):1355-1380, nov./dez. 2014 
las propuestas del gobierno de Lula para reestructurar el sector postal brasileño. Propuestas apoyaron la aprobación de la Ley 12.490 de 2011, que internacionalizó ECT, ampliaron segmentos de mercado de la empresa y la reestructuraron basado en el modelo de las corporaciones.

Palabras clave: correos; liberalización del mercado postal; regulación postal; reforma del modelo de organización.

The Brazilian postal system in transformation: proposals and changes in market regulation and restructuring of the organizational model of the Brazilian Post and Telegraph Company (19942011)

The aim of this article is to answer the question: what were the proposals and changes in the regulatory mechanisms of the Brazilian postal market and the organizational structure of the Brazilian Post and Telegraph Company (ECT) from 1994 up to 2011? From 1994 up to 2002, the federal government's proposal, submitted in 1999 by the "New Postal Law", provided for the creation of the National System of Post, liberalizing the postal market, creating a regulator body and turning ECT in a mixed economy company. Despite the disapproval of the bill, some of its proposals were taken, from 2008, by diagnoses and proposals of Lula's government to restructure the Brazilian postal sector. The proposals supported the approval of Law 12.490 from 2011, which internationalized ECT, expanding the company's market segments and restructuring the company based on the model of corporations.

KEYWORDs: post office; liberalization of the postal market; postal regulation; reform of the organizational model.

\section{Introdução}

Os sistemas de correios têm um vínculo histórico com os Estados nacionais. A regulação do setor postal baseou-se até as últimas duas décadas do século XX, e nos mais diversos países, no monopólio de alguns serviços e na exclusividade de um operador estatal. Além disso, desde as primeiras décadas do século $\mathrm{XX}$, os departamentos ou órgãos de correios de propriedade estatal estruturaram-se em grandes corporações verticalizadas e integradas. No entanto, com a ascensão e predomínio do neoliberalismo, governantes de diferentes países começaram a planejar, a partir de 1980, transformações radicais no setor. À época, entretanto, foram apresentados somente os primeiros passos em direção às propostas que seriam implementadas a partir dos anos 1990 (Crew e Kleindorfer, 2005).

Os motivos alegados para as mudanças na regulação do setor postal e as diretrizes que deveriam ser seguidas foram mais bem formulados e disseminados por agências internacionais como o Banco Mundial, União Postal Universal (UPU), Organização para a Cooperação e Desenvolvimento Econômico (Ocde) e Fundo Monetário Internacional (FMI). Em um relatório do Banco Mundial preparado com o auxílio da UPU e publicado em 1996, intitulado Redirecting mail: postal sector reform, foram apresentados as razões pelas quais as administrações postais deveriam ser transformadas e os caminhos a seguir. Dentre eles, o Banco Mundial listou a suposta ineficiência e inadequação dos operadores públicos às necessidades do 
mercado e da população. Os correios estatais, afirmou o Banco Mundial, não proporcionavam rentabilidade até mesmo para investimentos na melhoria dos serviços, o que motivou diferentes governos a buscarem reformas para o setor (Ranganathan e Dey, 1996). Nesse sentido, a Ocde (1999:21, tradução nossa) argumenta que

a contínua desregulamentação e liberalização dos outros setores da economia demonstraram os benefícios da competição na melhoria da qualidade, eficiência, inovação e redução dos preços aos consumidores, o que tem destacado a incongruência do monopólio e restrições para operação nesse setor.

Na análise do Banco Mundial, havia a necessidade imediata de uma reforma postal, sobretudo nos países em desenvolvimento. E isso seria justificado porque o setor seria ineficiente e insustentável, onerando os cofres públicos para cobrir déficits de operação. Para essa agência, o setor sofria para manter suas operações, que se tornavam cada vez mais obsoletas e ineficientes ao ponto de prejudicar o desenvolvimento de atividades econômicas que utilizavam a infraestrutura dos serviços postais (Ranganathan e Dey, 1996).

Essa alegada necessidade de reforma do setor postal deveria ser assumida e implantada como projeto de governo sem deixar que "ideias tradicionais" limitassem os objetivos e esforços das reformas, como propunha o Banco Mundial. Tais reformas, segundo a agência, deveriam compor um programa compreensível e integrado a ser seguido "imediatamente", sobretudo com a introdução de mecanismos de gestão alinhados à lógica de mercado. As reformas deveriam ser acompanhadas por mudanças nos mecanismos de regulação do setor. Até 1996, segundo o Banco Mundial, a maioria dos países mantinha o monopólio postal ou algum tipo de reserva de mercado. Para essa agência, a liberalização do mercado era/é importante para garantir a atuação dos operadores privados sem restrições. As propostas para transformações nos sistemas de correios abarcavam propostas, portanto, para 1) liberalização postal e quebra dos monopólios, 2) criação de novas formas de regulação para o setor e 3) corporatização e privatização dos correios estatais (Ranganathan e Dey, 1996).

Verifica-se que as transformações no setor postal internacional precisam ser compreendidas, portanto, a partir do vínculo que estabelecem com a hegemonia dos projetos neoliberais e seus receituários liberalizantes. Tal projeto, encampado por organismos multilaterais como Banco Mundial e Fundo Monetário Internacional (FMI), propunha um receituário que se tornou conhecido na América Latina como "Consenso de Washington", cujas práticas deveriam desencadear uma liberalização dos mercados nacionais, processos de privatização, livre circulação de capitais financeiros e reformulação das responsabilidades do Estado, que deveriam centrar-se na manutenção da livre competição e estabilização econômica, redução dos investimentos sociais e desoneração fiscal dos ricos, desregulamentação dos direitos trabalhistas etc., o que quase sempre desconsiderava a força de trabalho, a proteção social e os interesses públicos (Castells, 2005; Antunes, 1999, 2002; Castel, 1999; Anderson, 1995; Harvey, 2007). 
O sistema postal brasileiro foi reorganizado no século XX com a criação da Empresa Brasileira de Correios e Telégrafos (ECT) por meio do Decreto-Lei no 509, de 20 de março de 1969. A ECT foi criada como empresa pública, dado o ensejo da reforma administrativa expressa no Decreto-Lei no 200, de 25 de fevereiro de $1967 .{ }^{1}$ Uma inovação, à época, no cenário internacional. O objetivo era proporcionar à ECT uma gestão próxima da racionalidade técnica, adequando o setor postal estatal à lógica do setor privado. Com isso, os Correios passaram a transitar entre duas lógicas administrativas: uma empresarial e outra pública (Barros Neto, 2004). Garantiu-se à empresa a manutenção de seu patrimônio como pertencente integralmente à União. Além disso, garantiu-se autonomia à ECT para escolher - como na lógica empresarial — as estratégias de gestão necessárias à obtenção da eficiência e do lucro em suas operações.

Com a corporatização, os funcionários da ECT passaram a ser contratados pela Consolidação das Leis do Trabalho (CLT), o que possibilitou a livre contratação e demissão até a Constituição Federal de 1988, como mostrou Bovo (1997). Em 1978, a Lei no 6.538 foi promulgada e regulamentou os serviços postais monopolizados: cartas, encomendas e telégrafos. Na década de 1980, a ECT ampliou os serviços prestados com a criação de serviços expressos e ampliou as parcerias para prestação de serviços nas agências de atendimento em conjunto com outros órgãos da administração pública (Vergara e Cavalcanti, 1995), expandindo também sua capilaridade por meio do sistema de franquias, sobretudo no início da década de 1990 (Carvalho e Leite, 1996). Nesse interregno, combateu a violação ao monopólio postal acionando instrumentos legais ou, até mesmo, policiais até o início dos anos 1990 (Teixeira, 2013).

Somente na década de 1980 os países da Ocde deram início aos processos de transformação dos departamentos de correios em empresas públicas, como mostram Crew e Kleindorfer (2005). A diferença substancial entre a criação da ECT na década de 1960 e o início das reformas no cenário internacional está na intensidade do processo e na velocidade das mudanças. Sobretudo porque os países que iniciaram a reforma de seus serviços postais na década de 1980 já iniciaram as reestruturações dos modelos organizacionais considerando a liberalização do mercado postal e mesmo a privatização do sistema. Tais transformações internacionais influenciaram, na década de 1990, os rumos do sistema postal brasileiro.

Diante desse cenário, quais foram as propostas e as mudanças nos mecanismos de regulação do mercado postal e na estrutura organizacional da ECT entre 1994 e 2011 ?

A delimitação do período justifica-se por ser a partir da década de 1990 que as transformações no setor postal internacional intensificaram-se e também por permitir uma comparação entre estratégias políticas e gerenciais para o setor postal brasileiro entre dois importantes

\footnotetext{
${ }^{1}$ O Decreto-Lei no 200, de 25 de fevereiro de 1967, reorganizou o Estado brasileiro, que passou a organizar as entidades governamentais em administração direta (vinculadas à Presidência da República e ministérios) ou indireta (órgão com natureza jurídica própria), como autarquias, empresas públicas, sociedades de economia mista e fundações.
} 
períodos governamentais, o governo do presidente Fernando Henrique Cardoso (1994-2002) e o governo petista que se iniciou com o presidente Luiz Inácio Lula da Silva.

Além desta Introdução e dos aspectos metodológicos apresentados a seguir, o artigo possui cinco seções. Na primeira parte, descrevem-se as motivações e as tendências das transformações nos sistemas postais estrangeiros. Na sequência, as propostas e as mudanças no sistema postal brasileiro entre 1994 e 2011 são descritas analiticamente: primeiro entre 1994 e 2002 e, em seguida, entre 2002 e 2011. Na conclusão, apresenta-se uma análise comparativa entre as ações governamentais no setor postal no período e os impactos na transformação do sistema postal brasileiro.

\section{Aspectos metodológicos}

O artigo possui um recorte de natureza qualitativa. As informações primárias utilizadas no trabalho são provenientes de análise documental. Os dados foram levantados e compilados para mapear 1) o diagnóstico do setor postal em cada período governamental, 2) as propostas de mudança e 3) as mudanças implantadas.

Os dados foram compilados a partir de relatórios elaborados por agências multilaterais como o Banco Mundial, Ocde e UPU. Além desses, também foram utilizados relatórios de consultorias encomendadas pela União Europeia para analisar o setor postal naquele continente.

Documentos referentes ao governo do presidente Fernando Henrique Cardoso foram obtidos no Instituto Fernando Henrique Cardoso e no Instituto Sérgio Motta, patrocinadores do projeto Memória das Telecomunicações.

O acervo do jornal Folha de S.Paulo foi consultado para obtenção de informações sobre o setor postal. Além desse jornal, outros veículos de comunicação foram examinados e estão citados no texto e referenciados. Também foram coligidas informações nos acervos dos jornais corporativos CEP Correios e Correios do Brasil, publicações da ECT voltadas aos públicos externo e interno, respectivamente, com circulação entre 1999 e 2005.

A análise documental também foi realizada em manuais de gestão da empresa e relatórios empresariais, sociais e de administração. Os relatórios publicados entre 1999 e 2010 estão disponíveis no sítio eletrônico dos Correios. Para anos anteriores, é possível encontrar alguns no acervo do projeto Memória das Telecomunicações. A análise temática de conteúdo (Bardin, 2009), com viés qualitativo (Mozzato e Grzybovski, 2011), orientou o trabalho com os dados. Assim, fez-se uma leitura flutuante de todo o conteúdo levantado a partir de uma hipótese inicial: as transformações no setor estariam concatenadas à agenda neoliberal; a pesquisa, contudo, mostrou que a arena de embates no setor é mais complexa. O roteiro de leitura e análise foi organizado para mapear as motivações na proposição de mudanças, as propostas e as transformações efetivadas a partir de categorias significantes (Moraes, 1999): liberalização do mercado, marco regulatório, reestruturação dos modelos empresariais e privatização dos operadores estatais. 


\section{A "onda liberalizante" no setor postal internacional: argumentos acionados na proposição de mudanças}

Os países-membros da Ocde se reuniram em 1999 para debater os rumos do setor postal. À mesa de discussões foi dado o nome Promoting Competition in Postal Services. O objetivo, como está explícito, era debater e propor medidas para estimular e promover a competitividade nos serviços postais. Por competitividade, entendia-se a abertura dos mercados nacionais, com o fim dos monopólios dos operadores públicos e, de preferência, com a privatização dos entes estatais (Ocde, 1999).

De acordo com a Ocde (1999:1), até 1999 a maior parte dos países permanecia com o setor postal "intocado pelas ondas de reforma nos marcos regulatórios que transformaram o setor público". No mesmo sentido, o Banco Mundial chegou a afirmar que "enquanto significativos progressos em termos de reforma são feitos em outros setores do serviço público, o setor postal é um dos últimos bastiões da antiga ordem" (Ocde, 1999:21, tradução nossa).

A Ocde (1999), diante disso, sustentou a necessidade de reformas no setor postal capazes de a) eliminar o monopólio dos correios estatais, b) propiciar a abertura do mercado e c) criar condições para que os serviços obrigatórios de correio fossem assegurados.

O monopólio postal tem sido explicado, segundo Anderloni e Pilley (2002), por ele prover as condições para sustentação de uma estrutura de custos capaz de satisfazer as necessidades de um mercado interno com preços abaixo dos praticados por empresas que competem em mercados abertos. O objetivo do monopólio, assim, é subsidiar o custo dos serviços não comerciais prestados para entrega das correspondências em áreas de baixo retorno financeiro.

Na maioria dos países da Ocde (1999), as empresas estatais possuem o monopólio de certos segmentos do mercado postal. Esse monopólio é definido pelo preço ou peso de determinados serviços postais ou pela combinação de ambos (Horst, 2005). Para a Ocde (1999), as restrições e monopólios devem ser eliminados porque gerariam uma suposta distorção no mercado ao favorecer o operador postal estatal. Segundo a organização, as áreas que precisariam de um atendimento especial seriam abrangidas por uma melhor alocação dos recursos pelos operadores privados. O mercado competitivo, alegam, encontraria a solução para "esse problema" (sic).

De acordo com Anderloni e Pilley (2002), a universalidade dos serviços postais obrigatórios, garantida pela maioria das constituições nacionais, tem sido negligenciada ou eliminada. Segundo esses autores, os serviços postais precisam ser realizados por toda a extensão dos territórios nacionais e a custos razoáveis, o que nem sempre atende à lógica de mercado. Dessa forma, os serviços não comerciais justificariam a manutenção da reserva de mercado. Assim, a lógica dos operadores privados (maximizar lucros) e a necessidade de atender à população podem não ser convergentes, tornando-se a universalização dos serviços um aspecto problemático para os defensores da liberalização (Anderloni e Pilley, 2002). A despeito disso, onde a liberalização foi implantada tem se cogitado a criação de fundos com a contribuição de todos os operadores do mercado, públicos ou privados, para viabilizar as perdas decorrentes do atendimento às áreas não comerciais. 
O desenvolvimento tecnológico também tem sido um importante argumento acionado nos processos de transformação dos sistemas postais. As transformações tecnológicas apareceram nos argumentos de organismos multilaterais de forma determinista, segundo os quais

o desenvolvimento tecnológico e em especial das telecomunicações (por meio do fax, telefone, e-mail, internet etc.) estão erodindo o 'coração do negócio' dos sistemas de correios tradicionais, com potencial para ameaçar sua capacidade em continuar financiando as obrigações sociais com os serviços universais. (Ocde, 1999:21, tradução nossa)

Nessa mesma linha, o Banco Mundial já havia afirmado em 1996 que as tecnologias de informação eram responsáveis pela "necessidade" de liberalizar os mercados postais.

Esse argumento diferencia-se das transformações tecnológicas associadas à diminuição do fluxo de comunicação pessoal — cartas entre pessoas - , que representa pequenos percentuais no fluxo de objetos postais. Isso significa que as mudanças tecnológicas não afetaram o volume e tráfego de correspondências, embora tenha ocorrido uma mudança na natureza dos objetos postais, com o incremento das postagens vinculadas às atividades comerciais e a diminuição das correspondências pessoais. As transformações na tecnologia informacional, assim, podem ser situadas a partir de seu impacto no volume, fluxo e tipos de serviços postais prestados. Nesse sentido, por exemplo, em 1996 o então diretor da UPU destacou que o mercado para transporte de mercadorias tem crescido muito com o processo de globalização (Leavey, 1996).

Tais argumentos, todavia, não explicitam o lobby das empresas de courier interessadas nos mercados nacionais e a pressão que exerceram a favor da liberalização. Os projetos de reorganização do setor postal têm atendido também aos interesses de operadores postais multinacionais - pois, como argumentou a Ocde (1999), o crescimento das empresas no mercado postal aberto à competição tem sido limitado em razão de os correios estatais ainda terem "privilégios" nas operações.

Os fatores que têm motivado as mudanças no setor postal internacional são, portanto, vários. Mas devem ser destacados, concordando-se com Leavey (1996:15), os seguintes: 1) a emergência de grupos privados no setor de transportes e comunicações; 2) o lobby de grupos de operadores postais privados (courier), que pressionam para que os segmentos monopolizados sejam reduzidos ao máximo; 3) as orientações de agências e instituições como Banco Mundial, Ocde e Fundo Monetário Internacional (FMI), que exigiam programas de "ajustes estruturais" dos países para maior espaço ao capital privado e menor intervenção estatal; e 4) os mecanismos de integração dos mercados regionais na União Europeia.

Na próxima seção, discute-se como as propostas das agências internacionais foram implementadas nos contextos nacionais, destacando, principalmente, a repercussão que tiveram sobre os processos de reestruturação dos modelos empresariais e a privatização dos operadores postais estatais. 


\subsection{Reestruturação dos modelos empresariais: corporatização e privatização dos sistemas de correios no contexto internacional}

Para o Banco Mundial, o programa de reformas a ser implantado nos sistemas de correios deveria incluir crescentes reestruturações organizacionais, isto é, "reformas empresariais" capazes de melhorar a eficiência e os serviços. Para essa agência, as "reformas empresariais" são adotadas para redirecionar as ações dos operadores postais à lógica de mercado, ou seja, consistem na adoção de princípios empresariais para a gestão da entidade postal (Ranganathan e Dey, 1996).

Um passo adiante no processo é a corporatização (corporatization). O processo consiste na transformação de um órgão da administração pública direta — departamento, autarquia ou outro órgão de Estado - em uma corporação; a princípio, em uma empresa pública. Assim, trata-se de um processo que objetiva modificar os instrumentos legais para transformação jurídica dos correios estatais em empresas, desvinculando as entidades do poder público direto e garantindo autonomia gerencial e funcionamento com base no direito privado e empresarial mesmo quando o poder público continua a ser o proprietário ou acionista majoritário. Trata-se, portanto, de reformas organizacionais concatenadas à reestruturação produtiva e consequentes reformas dos modelos empresariais (Castells, 2005).

A reestruturação produtiva, de acordo com Castells (2005), engloba dois processos: 1) as transformações nos processos produtivos e nos métodos de gestão do trabalho focados na flexibilidade e a 2) reorganização das empresas, que tem transformado as estruturas (desenhos) organizacionais verticalizadas, rígidas e integradas para assumirem estruturas mais horizontalizadas, com menos departamentos e focadas em processos ou produtos. Dessa reorganização das empresas resultam a maior parte das terceirizações e a busca pela redução de custos, projetos de reengenharia, downsizing etc.

Ao observar e analisar os rumos das transformações postais nos países da Ocde, Anderloni e Pilley (2002) argumentam que as privatizações no setor têm seguido uma processualidade, o que é corroborado por Brandt (2007) ao estudar os países da União Europeia. Considerando que os operadores postais são inicialmente vinculados a ministérios ou departamentos de Estado, os passos no sentido da privatização têm sido transformá-los em empresas públicas com capital estatal, sociedades de economia mista com o Estado como sócio majoritário, sociedades de economia mista com ações preferenciais, sociedades anônimas majoritariamente de capital privado e, finalmente, a privatização total. Todavia, algumas "medidas de privatização" são encontradas no setor mesmo antes da privatização efetiva das entidades, como a transferência da rede de atendimento a terceiros por meio de franquias ou outros mecanismos contratuais.

O processo gradual de corporatização tem reformulado os modelos empresariais. Segundo Anderloni e Pilley (2002:18), os modelos organizacionais utilizados nas reestruturações organizacionais podem dividir horizontalmente o sistema postal estatal em diversas companhias, criando holdings, por exemplo, bem como a separação verticalizada para atuação em segmentos específicos de mercado. Dessa maneira, há um processo concomitante 
no cenário internacional de transformação dos sistemas de correios em empresas públicas e, em seguida, a fragmentação em empresas direcionadas a segmentos distintos de mercado ou integrantes de holdings, que frequentemente incorporam serviços bancários, seguradoras e telecomunicações.

É o caso, por exemplo, do Japão. Em 2003, os serviços postais japoneses passaram a ser prestados por uma empresa estatal que pouco tempo depois foi privatizada, sendo dividida em quatro empresas que passaram a integrar uma holding. O mesmo ocorreu anteriormente na Nova Zelândia, quando em 1987 a New Zealand Post \& Telecommunications foi dividida em três empresas: Correios da Nova Zelândia, Banco Postal e Telecom, sendo as duas últimas privatizadas; já a liberalização postal ocorreu em 1998, com a quebra do monopólio (Brandt, 2007; Anderloni e Pilley, 2002). Da mesma maneira, os 350 anos do correio sueco como órgão da administração pública findaram-se em 1994, quando foi transformado em sociedade anônima e renomeado Posten $\mathrm{AB}$. O objetivo foi retirar todo e qualquer auxílio estatal à empresa, que deveria competir abertamente no mercado (Brandt, 2007). Em 2002, houve a separação do banco postal, que passou a ser uma empresa à parte.

Na Holanda o caso é semelhante. Em 1989, o correio foi transformado em empresa pública (a KPN) e em 1994 em sociedade anônima. Em 1996, a KPN adquiriu a empresa australiana TNT. Em 1998, houve a divisão entre correios e telecomunicações, sendo a PTT correios e a KPN Telecom. Em 2002, por ambições internacionais, tornam-se subsidiárias da TNT Post Group (TPG). Em 2006, a companhia passou a ser TNT Post, subdividindo-se novamente em 2011 em duas: PostNL (correios) e TNT Express (Abvakabo, 2011).

Na Alemanha, as transformações postais também seguiram caminho similar. O processo de liberalização na Alemanha começou na década de 1980 e já em 1984 as autoridades alemãs abriram o mercado para alguns segmentos. De acordo com Brandt (2007), em 1989 o Federal Service Postal (Deutsche Bundespost) foi dividido em três companhias estatais: serviços postais (Postdienst), serviços financeiros (Postbank) e serviços de telecomunicações (Telekom). As três companhias tornaram-se legalmente empresas públicas da administração federal e independentes para decisões cotidianas, mas diretamente controladas pelo ministro dos Correios e Telecomunicações.

Com a separação da Deutsche Bundespost em três empresas, o monopólio foi mantido e continuou a ser aplicado pela Postdienst. Entretanto, desde 1994 foram feitos esforços para privatizar essas empresas e a partir de 1995 elas foram transformadas em sociedades de economia mista. Em um primeiro momento, o governo alemão ficou com todas as ações. Com essas mudanças, o serviço postal foi batizado de Deutsche Post AG (DPAG), que desde 1998 vinha comprando outras empresas. Em 2000, iniciou-se a privatização material da DPAG, com a oferta pública de ações. Com isso, a empresa foi renomeada para Deutsche Post World Net (DPWN/DHL) - empresa holding, com a DPAG como única acionista. Desde 2005, no entanto, investidores privados tornaram-se sócios majoritários da Deutsche World Net, comercialmente denominada de Deustsche Post DHL, transnacional líder do mercado global de logística e encomendas expressas (Brandt, 2007). 
Quadro 1

Reestruturação dos modelos empresariais e corporatização em países da Ocde

\begin{tabular}{|c|c|c|}
\hline País & $\begin{array}{l}\text { Ano em que deixou de ser } \\
\text { departamento de Estado }\end{array}$ & Sentido da reestruturação organizacional e corporatização \\
\hline Japão & 2003 & $\begin{array}{l}\text { Empresa estatal > Privatização > Divisão em quatro empresas de uma } \\
\text { holding. }\end{array}$ \\
\hline Nova Zelândia & 1987 & $\begin{array}{l}\text { Divisão da New Zealand Post \& Telecommunications em três empresas: } \\
\text { Correios da Nova Zelândia, Banco Postal e Telecom, sendo as duas } \\
\text { últimas posteriormente privatizadas. }\end{array}$ \\
\hline Suécia & 1994 & $\begin{array}{l}\text { Transformado em sociedade anônima. Em } 2002 \text { a Posten AB separou-se } \\
\text { do Banco Postal. }\end{array}$ \\
\hline Holanda & 1989 & $\begin{array}{l}\text { Empresa pública (1989) > Sociedade de economia mista (1994) } \\
>\text { Separação dos correios e telecomunicações (1998) > Torna-se } \\
\text { subsidiária de multinacional (2002) }\end{array}$ \\
\hline Alemanha & 1989 & $\begin{array}{l}\text { Dividido em três empresas públicas: correios, telecomunicações e banco } \\
\text { postal > Sociedades de economia mista (1995) > Início da privatização } \\
\text { em } 2000 \text { por meio de oferta de ações; torna-se DPWN/DHL > Em } \\
2005 \text { acionistas privados tornam-se majoritários da empresa líder do } \\
\text { mercado global de logística e encomendas expressas. }\end{array}$ \\
\hline
\end{tabular}

Fonte: Elaboração própria.

No Reino Unido, a principal mudança organizacional desde 1990 envolveu a transformação das companhias em sociedades anônimas em 2001, sendo o conglomerado de empresas postais denominado, a partir de 2002, de Royal Mail Group. São três operadores postais públicos: Royal Mail (cartas e pequenas encomendas), Parcelforce (encomendas maiores) e Post Office Counters (Agências de Correios), que são subsidiárias da Royal Mail Holdings, de propriedade governamental. Apesar da escolha em abrir vagarosamente o mercado, a partir de 2006 o Reino Unido optou por abrir completamente o mercado postal. Apesar da predominância dos correios estatais, há muitas pequenas empresas que prestam serviços locais, embora transnacionais como TNT e DHL também estejam no mercado e com boa fatia do segmento de encomendas expressas. As agências de atendimento são, em sua maioria, franqueadas e, portanto, privadas. São mais de 16 mil agências onde se realizam os mais diversos tipos de serviços. No caso do Reino Unido, a abertura comercial não levou à privatização do operador estatal, mas possibilitou um pequeno aumento das empresas que competem no mercado de cartas. Em 2013, contudo, iniciou-se uma discussão na Inglaterra sobre supostos benefícios - aumento de capital para investimentos e aumento da competitividade etc. — com a privatização do Royal Mail.

De acordo com a análise de Brandt (2007), a Alemanha realizou um processo de privatização radical de seu serviço postal e foi o único país a transferir totalmente ao setor privado o sistema postal. Os serviços postais depois do início do processo de liberalização no âmbito da comunidade ainda são prestados, predominantemente, por correios públicos. Assim, na 
maioria dos países da Europa, a presença do operador estatal ainda é predominante. A maior participação do operador público pode ser encontrada na Polônia, com 99\% do mercado, enquanto a menor está na Suécia, com 93\% do mercado compartilhado (a liberalização total do mercado ocorreu em 1992).

O processo de liberalização e reestruturação dos sistemas de correios no contexto internacional repercutiu na organização do sistema postal brasileiro. Na próxima seção, são apresentadas as estratégias para o setor postal brasileiro entre 1994 e 2011, ressaltando as continuidades e as rupturas entre o governo do presidente Fernando Henrique Cardoso (1994-2002), Luiz Inácio Lula da Silva (2002-10) e o primeiro ano de governo da presidente Dilma Rousseff.

\section{0 setor postal brasileiro durante o governo Fernando Henrique Cardoso (1994-2002): propostas para mudanças no modelo organizacional da ECT e no marco regulatório postal}

Ao iniciar o mandato em 1994, o presidente Fernando Henrique Cardoso (FHC) tomou medidas de grande impacto na ordem econômica brasileira e na estrutura de Estado. O setor de telecomunicações foi eleito como uma das prioridades do governo. Parte das estratégias para o setor — incluindo o setor postal — foi apresentada em 1995, na primeira versão do Programa de Recuperação e Ampliação do Sistema de Telecomunicações e do Sistema Postal (Paste). Tratava-se de uma mudança planejada, inicialmente, para a modernização da infraestrutura e do sistema gerencial e, posteriormente, possível privatização, como efetivamente ocorreu com as telecomunicações. São dois processos, portanto, articulados e aparentemente paradoxais: moderniza-se o setor e, em seguida, o privatiza. A explicação oficial para isso, todavia, justifica a modernização antes de quaisquer medidas de privatização como forma de viabilizar a sobrevivência dos operadores estatais em um mercado competitivo (Brasil, 1997).

A proposta de modernização do sistema postal estava baseada no aumento da oferta de serviços, na modernização tecnológica e na consolidação e ampliação do papel social dos Correios como agente prestador de serviços públicos. Para isso, o discurso de posse do ministro das Comunicações do primeiro mandato de FHC, Sérgio Motta, prenunciava quais seriam as principais diretrizes do governo para o setor:

Formulação de um amplo programa de investimentos para o período 1995/1999, com enlace até 2003, a ser executado pelas empresas do setor de comunicações — públicas e privadas —, condizente com o elenco de diretrizes e metas traçadas para os serviços de telecomunicações e postais. (...). Implementação de novo modelo institucional para o setor (postal e de telecomunicações), incentivando a competição na exploração dos serviços, com intensa participação de capitais privados e implantação do cenário de transição para privatização integral da operação do setor (...). Modernização dos serviços postais. (Brasil, 1996:2, grifo nosso) 
Os projetos e programas do governo FHC, assim, pressupunham a modernização do setor postal antes de uma possível privatização. Os projetos apresentados na primeira versão do Paste foram executados entre 1995 e 1997 e contemplaram planos de modernização dos Correios em três setores: mecanização da triagem, informatização das agências e racionalização da rede postal aérea noturna. Concomitante a esses investimentos para modernização da empresa, "iniciaram-se também os estudos sobre a reestruturação institucional" da ECT (Brasil, 1998:9, grifo nosso).

O governo do presidente Fernando Henrique Cardoso justificou as alterações propostas para o setor postal brasileiro de forma semelhante às agências multilaterais, alegando que os sistemas postais foram operados desde a década de 1960 sob regime de monopólio e com controle estatal, modelo que estaria defasado. Para o governo FHC, com as transformações ocorridas na economia capitalista em decorrência do "ambiente concorrencial" dos anos de 1980 e 1990, era preciso uma "reforma" no setor postal para adequá-lo às novas circunstâncias. Esse cenário forjado a partir das transformações no processo de acumulação capitalista exigia “(...) uma organização postal mais moderna e orientada para o mercado” (Brasil, 1997:15).

Com isso, o setor postal passou a ser alvo de estratégias de modernização, sobretudo em termos gerenciais, em um processo de modernização administrativa da máquina pública com instrumentos empresariais. Proposta alinhada, portanto, ao discurso da reforma do Estado e à administração pública gerencial, como apresentada em Pereira e Spink (1998). Ao mesmo tempo, foi nesse período que, “(...) observando o grande potencial de mercado, a iniciativa privada redescobre os Correios como atividade empresarial rentável" o que na perspectiva do governo FHC faz com que "(...) a atividade postal deixe de ser atividade exclusiva do Estado e passe (a) conviver com capitais privados" (Brasil, 1997:16).

Com os processos de modernização em andamento, o governo FHC atentou-se para o processo de reestruturação dos operadores postais na Europa - sobretudo para medidas como a adoção de um regulador postal, a abertura do mercado entre países da União Europeia, a discussão sobre serviços universais, a forma de gestão do operador postal estatal e as formas graduais de privatização - e tratou de elaborar um novo modelo organizacional e de regulação para o setor postal brasileiro.

Para isso, o Ministério das Comunicações (Brasil, 1998) desenvolveu um projeto para o setor postal brasileiro que foi implantado a partir de 1997, denominado Reforma Estrutural do Setor Postal Brasileiro (Resp). As diretrizes acionadas na elaboração da reestruturação postal abarcavam os seguintes aspectos:

1) Reforma Regulamentar do Setor Postal: definição de um novo modelo de exploração dos serviços postais no Brasil, envolvendo questões fundamentais como serviços universais, monopólio, controle da Empresa Brasileira de Correios e Telégrafos — ECT, órgão regulador, etc.;

2) Reforma comercial e organizacional da ECT: modernização da empresa, (...) preparando-a para atuar em um novo contexto regulamentar a ser implantado no setor;

3) Serviços Financeiros Postais: a utilização da infraestrutura de atendimento da ECT para que, em parceria com o Sistema Financeiro Nacional, sejam prestados serviços financeiros básicos à 
parcela da sociedade atualmente não atendida pela rede bancária, isto é, a população rural e a população urbana de baixa renda. (Brasil, 1998:9)

A primeira diretriz — a reforma estrutural do setor — norteava-se pela mesma lógica das transformações no setor de telecomunicações e objetivava criar novos parâmetros para a prestação dos serviços. Ao mesmo tempo, seriam buscadas alternativas para incrementar os serviços comerciais prestados pela ECT, com a oferta de serviços bancários por meio da rede de atendimento.

Em 1998 o governo encerrou o Resp, o qual elaborou projetos para a reforma regulamentar, comercial e organizacional da ECT, e cujo principal produto foi convertido pelo presidente FHC no Projeto de Lei Geral do Sistema Nacional de Correios (Projeto de Lei no 1.491/1999), propondo a transformação do setor.

O projeto de lei que propunha o Sistema Nacional de Correios, denominado à época de nova Lei Postal, foi desenvolvido e organizado para transformar radicalmente o setor. Sua concepção e desenvolvimento tiveram como inspiração as orientações da UPU, Banco Mundial e reformas realizadas no âmbito da Ocde, sobretudo de países situados na União Europeia. A inspiração ideológica neoliberal, portanto, orientou a concepção do projeto.

Nas palavras de Egydio Bianchi (1999a:3), presidente da ECT à época, era preciso reformular os serviços postais porque

(...) reconheceu-se que o modelo estruturado na década de 70 dava sinais de fadiga, ameaçando padrões de qualidade duramente conquistados em decorrência de fatores adversos surgidos ao longo de quase dez anos: aumento do tráfego postal, investimentos inexpressivos, atraso tecnológico, congelamento do quadro de pessoal, ingerências políticas, etc. Ao mesmo tempo, o governo e a ECT passaram a ficar atentos às grandes transformações ocorridas no sistema postal no mundo, impulsionadas pelas novas tecnologias de comunicação e pela desregulação dos mercados.

O governo FHC esperava aprovar rapidamente as mudanças postais no Congresso Nacional, tanto que contava com a tramitação do projeto em regime de urgência. Entretanto, parlamentares da própria base aliada do governo resistiram à votação do projeto em convocação extraordinária. Durante a tramitação nas Comissões, foram apresentadas mais de 99 emendas pela base aliada do governo e por partidos de oposição, principalmente pelo Partido dos Trabalhadores (PT). Todavia, o plano do governo era aprovar a nova Lei Postal tal como apresentada.

O que propunha, afinal, a nova Lei?

O projeto de lei previa a criação do Sistema Nacional de Correios. A ECT era, até então, a única empresa autorizada pela legislação a atuar em todos os segmentos postais. Em razão disso, a reforma postal criaria o Sistema Nacional de Correios, que seria formado pelas empresas privadas que entrassem no mercado postal, pelo correio estatal e pela agência reguladora a ser criada, formando, assim, a infraestrutura postal do país. 
A nova lei postal propunha também a liberalização do mercado postal. Com isso, evidentemente, o monopólio da ECT seria eliminado. Assim, o correio estatal e as empresas privadas passariam a oferecer serviços postais, conceito que abarcava modalidades de serviços postais (serviços tradicionais, isto é, envio de objetos postais), serviços parapostais (serviços financeiros prestados em agências, isto é, serviços prestados por um banco postal) e serviços de interesse social (atendimento de pontos carentes de serviços básicos).

Cabe destacar, dentre os serviços parapostais, a proposta de criação de um banco postal para atuar em parceria com as agências postais dos Correios. A prestação de serviços financeiros por meio do banco postal incluiria serviços de poupança, conta-corrente, transferência bancária, recebimento de contas etc., ou seja, serviços bancários básicos, oferecidos principalmente à população de baixa renda e de localidades distantes das metrópoles.

Dessa forma, o Sistema Nacional de Correios possibilitaria aos operadores postais prestar diversos serviços postais, desde que obtivessem autorização. A necessidade de autorização para a entrada de algum operador no mercado implica um Regime de Exploração para prestação de serviços, havendo para isso instrumentos como concessão, permissão e autorização.

E quais seriam os impactos diretos sobre a ECT? De acordo com o projeto de lei, a ECT seria transformada em Correios do Brasil S.A. A ECT deixaria de ser uma empresa pública para se transformar em uma empresa de economia mista e, a partir disso, teria condições de criar subsidiárias, participar de outras empresas, negociar suas ações etc. O governo FHC, no entanto, alegava que não pretendia privatizar a ECT, isto é, as ações da Correios do Brasil S.A seriam majoritariamente da União. Isso, todavia, não impediria que a empresa fosse transformada em subsidiárias passíveis de venda. Em relação ao monopólio postal, o projeto da nova Lei Postal previa uma atuação exclusiva da Correios do Brasil S.A. em alguns segmentos - como a exploração de cartas, telegramas, cartões postais e malotes - pelo prazo máximo de 10 anos, podendo ser reduzido para cinco. Ao final desse prazo, a liberalização do mercado seria total. Buscou-se, assim, uma quebra gradual do monopólio, como ocorreu na União Europeia.

Para atuar em um mercado aberto à competição, a Agência Nacional de Serviços de Correios seria criada com os objetivos de regular, controlar e fiscalizar o Sistema Nacional de Correios. Caberia ainda à agência reguladora garantir a realização dos serviços postais essenciais, a manutenção da competição e a defesa dos interesses dos consumidores. A criação de uma agência reguladora, assim, retiraria do governo o poder de regulação do setor, transferindo-o a um órgão supostamente independente capaz de arbitrar sobre o mercado postal.

A proposta alteraria, portanto, significativamente o sistema postal brasileiro e interferia em diversos interesses corporativos. Diante disso, como a nova lei postal foi recebida pelos empresários interessados no setor?

\section{1 Estratégias dissonantes: o papel dos empresários na derrota da "nova Lei Postal"}

De acordo com o então ministro das comunicações Pimenta da Veiga, o projeto da nova Lei Postal “(...) chega com força ao legislativo [e] marcado pela legitimidade", já que teria sido 
submetido à sociedade e debatido por vários setores, propiciando o entendimento necessário à aprovação do projeto de lei. Assim, as resistências seriam menores no Congresso Nacional (A segunda..., 1999).

Apesar do otimismo do ministro, o presidente da ECT, Egydio Bianchi, escreveu sobre a existência de "mal-entendidos" no projeto antes mesmo de ele ser enviado ao Congresso. De acordo com o presidente da ECT, o primeiro "mal-entendido" versava sobre a privatização da ECT. Segundo ele (Bianchi, 1999b:3), "ao contrário do que se alardeia", "não está prevista a privatização dos Correios", embora "preparam-se para uma profunda reformulação, capacitando-se para disputar novos mercados, adotando parcerias e abrindo oportunidades para a ação empresarial privada".

Além disso, os "mal-entendidos", como disse o presidente da ECT, continuaram. Inclusive por parte de empresários do setor postal, que em tese deveriam estar comprometidos com o projeto. Nesse sentido, o presidente da então DHL afirmou à Folha de S.Paulo estar em campanha junto aos seus clientes contra o projeto da nova Lei Postal porque ela garantiria o monopólio da ECT, que estaria sendo ampliado inclusive por meio da rede de atendimento (Contra..., 1999). Dessa forma, empresários do setor começaram a alegar que o projeto de lei não eliminava o monopólio postal, pois ele permaneceria com a Correios do Brasil S.A. por mais 10 anos.

Na análise do Sindicato Nacional das Empresas de Encomenda (Sineex), o projeto de lei ampliava o monopólio postal ao exigir que as empresas se submetessem ao órgão regulador. Para a Sineex, a garantia do monopólio - mesmo em apenas um segmento do mercado tornava o projeto inconstitucional, bem como as possíveis ingerências do Estado na iniciativa privada por meio de um órgão regulador. A entidade sugeria, ainda, que contas, boletos e cobranças fossem retirados da definição de "cartas" sob monopólio (Bayma, 1999).

No mesmo sentido, o Comitê das Empresas de Encomendas Expressas manifestou-se "contra abusos claros, ausências de regras explícitas e indispensáveis à regulamentação e à prestação dos serviços ao consumidor" (Bayma, 1999:27), o que abarcava a ausência de um detalhamento das atividades de um banco postal, bem como aspectos como a extinção e concessão de regimes de exploração. Além disso, aspectos como o poder de regulação da agência a ser criada foram muito criticados. Alegando representar um setor com mais de um milhão de trabalhadores, o Comitê afirmou estar preocupado com os rumos da competição privilegiada da Correios do Brasil S.A. e as possíveis consequências para os trabalhadores. Em um contrassenso, o Comitê também afirmara estar "preocupado" com a estabilidade e emprego dos funcionários da ECT.

Na mesma direção, de acordo com Bayma (1999), a Associação Nacional dos Transportadores de Carga — que afirmava ter mais de 12 mil associados — alegava realizar atividades correlatas aos serviços postais, mas que não devia subordinar-se ao órgão regulador postal, mas à Agência Nacional de Transportes Aéreos. Com isso, passou a defender, inclusive, a completa desregulação do setor, bem como a garantia de retorno financeiro pela concessão. Segundo o posicionamento da Associação, seguindo argumentos de outros grupos empresariais, o projeto de lei reforçaria o poder da Correios do Brasil S.A. 
Em meio à disputa, a definição dos objetos postais submetidos ao monopólio pela Correios do Brasil S.A. foi um dos elementos que mais criou atritos entre o governo e empresários. A reserva de mercado para "malotes" ou "correspondência agrupada" poderia ampliar, no entendimento de grupos empresariais, o poder da empresa estatal (Pavoni Júnior e Vasques, 2001). Com isso, entidades envolvidas com o comércio eletrônico sentiram-se ameaçadas com o impacto do projeto de lei aos seus negócios e também manifestaram sua desaprovação.

Assim, a Câmara Brasileira de Comércio Eletrônico associou-se às entidades empresariais como Confederação Nacional da Indústria, Confederação Nacional dos Transportes, Federação das Indústrias do Estado de São Paulo, Associação Brasileira das Empresas de Transporte Internacional e Expresso de Cartas e Câmara Americana de Comércio para pressionar os parlamentares contra a nova Lei Postal "monopolista" que dificultaria, segundo as associações empresariais, as exportações, o comércio eletrônico e geraria insegurança jurídica sobre as atividades postais em decorrência da ambiguidade da definição de "carta". De acordo com o então secretário de serviços postais, a oposição de grupos empresariais ocorreu porque "as pessoas não tiveram tempo ou vontade de ler a lei inteira". A despeito disso, o Comitê das Empresas de Encomendas Expressas afirmava que "eles (os integrantes do governo) querem engordar a empresa para a privatização" (Pavoni Júnior e Vasques, 2001).

As divergências com o projeto da nova Lei Postal, portanto, estavam centradas em um suposto excesso de regulação de mercado, na indefinição da área de atuação das agências da nova empresa de Correios como prestadora de serviços financeiros e, principalmente, na delimitação do segmento de mercado reservado por mais 10 anos.

Diante das posições que ora alegavam o interesse do governo FHC na privatização, ora a busca por reforçar o monopólio da empresa estatal, o então presidente da ECT tentou se explicar. Nas palavras de Egydio Bianchi (1999a:3),

Para ter uma ideia da disparidade de opiniões, dizia-se, (...), que o governo estaria preparando a "privatização" dos Correios. Como o anteprojeto da nova lei postal era ainda pouco conhecido, atribuímos tal afirmação à afoiteza, logo superada pelo conhecimento mais detalhado da proposta. Recentemente, alguns setores passaram a cometer outro tipo de engano: o governo estaria tentando "ampliar o monopólio" dos Correios. Como se vê, entre um e outro equívoco há um enorme paradoxo.

Desde o início temos deixado bem claro que os princípios da grande reforma do sistema postal estão baseados na extinção do monopólio, na regularização do setor, no estímulo à competição, na preparação dos Correios para as disputas do mercado e na preservação dos serviços postais. E isso tudo não é propriamente sinônimo de privatização do sistema, muito aquém de ampliação do monopólio postal.

De acordo com Bianchi (1999b), a maior parte dos atritos decorria de dois elementos presentes no projeto de lei: o entendimento sobre exclusividade e essencialidade dos serviços e a necessidade de autorização para a livre-iniciativa atuar no mercado postal. O então presidente da ECT explicou que serviços essenciais eram os serviços mínimos que o governo 
iria garantir à sociedade, abarcando objetos postais sem urgência e com até dois quilos. Isso buscava, segundo ele, resguardar a população em caso de operadores privados não atenderem adequadamente o segmento. Os serviços exclusivos, por sua vez, referiam-se aos segmentos de mercado que permaneceriam sob monopólio por no máximo mais 10 anos após a aprovação da lei, o que incluía as cartas, telegramas, cartão postal e malotes (ou correspondência agrupada). Segundo Egydio Bianchi, eram os mesmos serviços cujo monopólio estava previsto pela legislação vigente. A diferença estava na introdução de um prazo para a liberalização. Sobre a necessidade de autorização e submissão a um regime de exploração, a explicação do presidente da ECT vinculou a proposta do governo ao aumento da competitividade no mercado, favorecendo a população. A regulação, assim, seria para normatizar a forma como os serviços poderiam ser mais bem realizados.

Para o então presidente da DHL no Brasil, Michael Canon (1999), apesar de o presidente da ECT citar "princípios louváveis" na defesa do projeto de lei - extinção do monopólio, estímulo à competição, regularização do setor etc. —, eles não se sustentavam nos artigos do projeto. Segundo ele, “(...) o que transparece é a nostalgia da era dos privilégios das estatais, um passo na contramão em tempos de abertura de mercado e de privatização de serviços públicos”, e ainda afirma que o governo optara pela manutenção do monopólio, “(...) ainda que isso signifique caminhar na contramão de outros setores" (Canon, 1999:3).

Dentre os que questionaram o projeto, havia também a Associação Nacional de Jornais, que argumentava a favor do que entendia ser a "liberdade de imprensa", isto é, a autonomia das empresas de comunicação na distribuição de jornais e revistas. A lei previa que toda empresa era livre para distribuir sua própria correspondência, mas não para distribuir produtos de terceiros. Para isso, era preciso autorização e pagar taxas à agência reguladora (Nassif, 1999). Assim, empresários da comunicação usaram o mote da "liberdade de imprensa" a favor de seus interesses comerciais.

A oposição ao projeto entre empresários brasileiros e grupos internacionais em atuação no mercado nacional, portanto, foi grande e intensa. Em razão disso, audiências públicas foram realizadas na Câmara dos Deputados para discutir a nova Lei Postal, sendo algumas solicitadas por grupos e associações empresariais.

O governo FHC previa uma tramitação rápida do projeto de lei no Congresso Nacional, não prevendo a divergência e resistência de grupos empresariais, portanto. Não obstante, o governo pretendia a aprovação da Lei Postal na íntegra, sendo todas as emendas e substitutivos rejeitados. Isso explica por que o projeto, apresentado em 1999 na Câmara dos Deputados, não fora posto em votação até 2001 — véspera das eleições.

Ao perder força política no Congresso e legitimidade junto aos grupos empresariais, o projeto estendeu-se por várias Comissões até a eleição do presidente Luís Inácio Lula da Silva em 2002, que solicitou no ano seguinte a retirada do projeto da nova Lei Postal.

A chegada ao poder do presidente Luís Inácio da Silva, no entanto, não suprimiu os projetos de reforma no sistema postal brasileiro. Como analisado a seguir, esse governo e o da presidente Dilma Rousseff reestruturaram a ECT. 


\section{A reestruturação organizacional dos Correios durante os governos Lula e Dilma Rousseff: aprofunda-se a corporatização}

A despeito de se apresentar como agente da descontinuidade com o ideário neoliberal da década de 1990, o governo do presidente Lula caracterizou-se, em aspectos da política macroeconômica, pela continuidade com práticas neoliberais. Apesar disso, os papéis atribuídos ao Estado pelos governos FHC e Lula são divergentes. Enquanto aquele defendia uma intervenção mínima na economia, este propunha certo protagonismo estatal em atividades econômicas e sociais (Boito Júnior, 2005; Antunes, 2004; Filgueiras e Gonçalves, 2007). De forma semelhante, Singer (2009), ao analisar o que denomina lulismo, afirma que o governo do presidente Luís Inácio se caracterizou pela manutenção da estabilidade macroeconômica e por uma ação distributiva do Estado.

De acordo com Abrucio (2007), em análise sobre a recente gestão pública brasileira, observa-se também no governo Lula uma continuidade na administração pública federal de práticas e iniciativas implantadas no governo FHC, sobretudo no campo da modernização e planejamento da gestão. Apesar disso, destaca o autor, o governo petista tem sido bastante criticado pela visibilidade do aparelhamento de cargos públicos por correligionários. Como discute Teixeira (2013), o aparelhamento político de cargos de gestão na ECT tem sido, apesar da controvérsia, apontado por parte de veículos de comunicação como responsável por uma "crise nos Correios".

Nesse contexto, quais foram as propostas do governo petista para a regulação do mercado postal e a reestruturação organizacional da ECT?

Em 2008, o ministro das Comunicações Hélio Costa encaminhou ao presidente Luiz Inácio Lula da Silva solicitação de criação de grupo de trabalho para analisar e propor mudanças no setor postal brasileiro. O presidente Luiz Inácio determinou a criação do Grupo de Trabalho Interministerial (GTI) no segundo semestre de 2008, com a finalidade de elaborar estudos e propor diretrizes para a modernização da ECT. As atividades iniciaram-se formalmente em fevereiro de 2009, sendo o GTI composto por representantes do Ministério das Comunicações, da Casa Civil da Presidência da República, do Ministério do Planejamento, Orçamento e Gestão, do Ministério da Fazenda e da ECT (Brasil, 2009).

A solicitação do ministro das Comunicações para criação do GTI foi justificada pelo contexto em que a ECT vinha atuando. Tal contexto dizia respeito à própria estrutura organizacional e de mercado da ECT e aos rumos do setor postal mundial. De acordo com o relatório final do GTI (Brasil, 2009), o mercado postal até a década de 1990 pode ser considerado estável. No entanto, desde então o processo de globalização, as novas tecnologias de informação e comunicação, além da intensificação do comércio internacional, têm impactado o mercado postal. Esses elementos, de acordo com os integrantes do GTI, criaram um novo ambiente de atuação para a ECT.

Além disso, a intensa transformação internacional no mercado postal, com processos de privatização, fusões, formação de oligopólios para atuação em âmbito internacional, tem pressionado o mercado brasileiro, inclusive com a aquisição de empresas de médio porte que 
atuam em segmentos específicos de mercado, sobretudo os mais rentáveis de encomendas em grandes centros urbanos. Essas empresas, que atuam sem uma regulação postal específica, representariam uma ameaça de mercado à ECT (Brasil, 2009).

Somado a isso, haveria também aspectos internos à ECT restritivos à sua atuação de forma mais eficiente. Tais aspectos relacionavam-se à gestão da estatal e seu modelo de corporação. Isso porque a estatal prevê o acirramento da competição e a consequente necessidade de investimentos para manutenção da competitividade, o que demandaria, principalmente, flexibilidade corporativa para acionar estratégias gerenciais consideradas mais adequadas para manutenção do domínio de mercado. Diante disso, o Grupo de Trabalho sugeriu o aprofundamento da corporatização da ECT.

Verifica-se que as motivações para formulação de estratégias visando mudanças na ECT tanto no governo do presidente Fernando Henrique quanto no governo do presidente Luiz Inácio são as mesmas, ou seja, aumento da competição, transformações tecnológicas, mercado globalizado etc. Contudo, há uma diferença central entre esses dois momentos da história da ECT: enquanto no governo FHC previa-se a abertura do mercado postal, o governo Lula justificava as mudanças na estatal como forma de fortalecê-la para atuar em um mercado mais acirrado.

Os trabalhos do GTI foram divididos em serviços prestados, infraestrutura e gestão. Segundo o GTI (Brasil, 2009:17), as restrições estruturais da ECT resumiam-se aos seguintes pontos:

a) Âmbito de atuação restrito, impedindo a atuação da empresa nos mercados internacionais;

b) Limitação do objeto social, o que dificulta a atuação da empresa em novos segmentos correlatos e afins, bem como inibe a atualização dos serviços, em especial na adoção de novas tecnologias;

c) Limitação legal para contratação de serviços para a Rede Postal Noturna;

d) Modelo empresarial desatualizado, especialmente no que concerne à personalidade jurídica da ECT, que ainda se encontra indefinida; e

e) Situação precária de governança corporativa, resultado de modelo institucional e organizacional superados.

Verifica-se, diante dos aspectos elencados, que a impossibilidade de a ECT atuar diretamente em território estrangeiro - em decorrência do decreto de sua criação que delimitava o território nacional como âmbito de atuação - foi apontada como uma restrição de mercado a ser superada. Isso porque a ECT vinha se restringindo a realizar acordos com correios oficiais e, eventualmente, contratos com operadores privados. De acordo com o GTI (Brasil, 2009:17), isso fragilizou a atuação internacional da ECT, sendo a

origem dessa fragilidade (...) a histórica prioridade e exclusividade conferida às parcerias com correios oficiais, cuja reputação, (...), muitas das vezes, [são] bem inferiores (...). Muitos dos correios oficiais, especialmente nas nações em desenvolvimento, não têm condições de garantir níveis mínimos de prazos e condições de entrega. 
Com essa leitura, o GTI e a ECT propuseram a ampliação do mercado de atuação da ECT, sobretudo pela internacionalização de sua atuação, seja por meio de parcerias com empresas privadas transnacionais ou mesmo pela provisão direta de serviços em territórios estrangeiros. Dentre outros aspectos, isso poderia melhorar a qualidade dos serviços dos clientes brasileiros, recuperar as receitas perdidas com os baixos serviços prestados pelos correios oficiais estrangeiros, ampliar a oferta de serviços etc. (Brasil, 2009).

Além disso, a estratégia do governo federal fica evidente: expandir as atividades da ECT para a América Latina. Segundo a estatal, os serviços postais na região são deficientes, o que lhe garante uma vantagem no mercado postal regional, sobretudo ao prestar suporte às atividades empresariais originadas no Brasil. Mesmo com a ECT prestando consultorias para melhorar o desempenho operacional de correios oficiais, a qualidade dos serviços prestados por eles não tem sido suficiente para atender "aos negócios privados e o processo de crescente integração regional que o governo brasileiro incentiva de modo permanente" (Brasil, 2009:18).

O governo do presidente Luiz Inácio justificou essa estratégia com a apresentação de dados sobre a rede de atendimento da ECT, que representa 37\% de toda a rede de atendimento da região. Ao mesmo tempo, $80 \%$ do volume de correspondências e $82 \%$ da receita postal da região são da ECT, bem como os melhores níveis de qualidade dos serviços ( $D+1$ no Brasil e ausência de critérios de qualidade na região). Enquanto os países da região buscam implantar um serviço de encomenda de qualidade, a ECT oferece uma ampla gama de serviços. Em outras palavras, a vantagem competitiva da estatal brasileira justificava sua expansão para países da América Latina, cabendo, portanto, uma reforma legal para isso. Dessa forma, redefiniu-se o espaço de atuação da ECT, que agora pode atuar tanto em território nacional como internacional. Assim, foram atendidas as estratégias de internacionalização da estatal.

Os estudos do GTI também apontaram o "modelo empresarial desatualizado" da ECT como outro ponto a ser alterado e, para isso, propuseram a reestruturação do modelo organizacional da estatal como forma de proporcionar à empresa maior segurança jurídica e rapidez às ações gerenciais.

O processo de corporatização da ECT na década de 1960 a transformou em uma empresa pública, mas não a definiu como uma companhia limitada ou sociedade anônima, o que na opinião do governo Lula dificultava a adoção de mecanismos eficientes de governança. Assim, os membros do governo recomendaram que a ECT fosse reestruturada como uma empresa pública sob a forma de sociedade anônima com capital exclusivamente da União (podendo ser posteriormente pulverizado e compartilhado com estados e municípios). Com essa medida, "os institutos da imunidade tributária e do precatório estariam preservados para (...) garantia da universalização dos serviços, mantendo a natureza (...) de interesse social, e afastando a possível interpretação de exploração de atividade econômica" dos serviços postais (Brasil, 2009:25).

A proposição do governo Lula pela transformação da ECT em empresa organizada sob a forma de sociedade anônima coaduna-se com o processo de corporatização. Todavia, se 
na década de 1960 a ECT foi pioneira nesse processo no cenário internacional, o aprofundamento do processo de corporatização — transformando a ECT em sociedade anônima — já havia sido iniciado no contexto internacional a partir da década de 1990 com o objetivo de privatizar os serviços postais.

A reestruturação do modelo organizacional, aprofundando o processo de corporatização, foi realizada, no entanto, somente depois das eleições presidenciais de 2010, quando a presidente Dilma Rousseff foi eleita. Uma de suas primeiras ações foi editar a Medida Provisó-

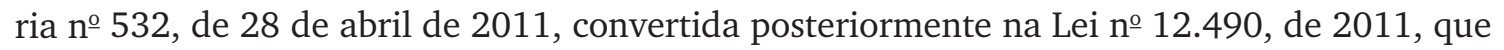
incorporou debates e proposições do GTI.

A presidente Dilma Rousseff, ao capitanear o processo de reestruturação organizacional da ECT, não deixou de incorporar o aspecto mais polêmico das medidas propostas pelo GTI: aprofundar a corporatização da empresa. Para isso, a Lei no 12.490 , de 2011, trouxe também a seguinte inovação: “Art. 21-A. Aplica-se subsidiariamente a este Decreto-Lei a Lei no 6.404, de 15 de dezembro de 1976" (grifo nosso).

A estratégia política do governo federal foi suprimir a expressão "sociedade anônima" do texto da lei, mas sem deixar de incorporar os princípios e instrumentos da Lei das Sociedades Anônimas (Lei no 6.404, de 17 de dezembro de 1976). Assim, não houve a abertura de capital da empresa, que continua sendo integralmente da União, mas a adequação organizacional e administrativa aos princípios da corporatização.

Para a adequação da ECT às diretrizes das sociedades anônimas, a estrutura organizacional da estatal foi alterada, com o acréscimo de órgãos de natureza administrativa. Dessa maneira, se antes a administração da ECT estava a cargo de um presidente responsável pela Diretoria, com a reestruturação organizacional, passou a contar com um Conselho de Administração, uma Diretoria Executiva (formada pelo presidente e oito vice-presidentes) e um Conselho Fiscal, atendendo aos anseios por melhorias na governança corporativa.

Como órgão máximo de decisão, criou-se na ECT a Assembleia Geral para deliberação das questões mais relevantes, com publicação de ata com as decisões tomadas. O Conselho de Administração, responsável por orientar e definir as estratégias de negócios, os objetivos corporativos e monitorar os resultados, inclui no processo decisório sete membros. Destes, quatro são indicados pelo ministro das Comunicações. Além disso, fazem parte do Conselho de Administração o presidente da ECT, um integrante indicado pelo ministro do Planejamento, Orçamento e Gestão e um representante dos trabalhadores escolhido em eleição nacional.

Além disso, a reestruturação organizacional garantiu à estatal a possibilidade de constituir subsidiárias, adquirir o controle ou participação acionária em empreendimentos empresariais e converter-se em controladora de uma holding. Com essa medida, é possível a ECT, por exemplo, criar ou adquirir empresas de transporte aéreo ou participar de projetos de seu interesse ou do governo federal - como o projeto do trem de alta velocidade entre as cidades de Campinas e Rio de Janeiro - que proporcionariam maior agilidade ao transporte de objetos postais e livraria a empresa de problemas operacionais, como os gargalos relacionados com a rede postal aérea noturna. 


\section{6. À guisa de conclusão}

O foco deste artigo esteve nas propostas e nas mudanças na regulação do mercado postal brasileiro e na estrutura organizacional da ECT entre 1994 e 2011. O quadro 2 sintetiza e compara alguns dos principais elementos em discussão e como foram tratados pelos distintos governos durante o período analisado.

$$
\text { Quadro } 2
$$

Propostas e mudanças na ECT entre 1994 e 2011

\begin{tabular}{|c|c|c|}
\hline & Governo FHC & Governos Lula/Dilma Rousseff \\
\hline Abertura de mercado & $\begin{array}{l}\text { Propôs abertura do mercado postal com } \\
\text { eliminação gradual do monopólio }\end{array}$ & $\begin{array}{l}\text { Manutenção das restrições de mercado } \\
\text { com defesa do monopólio }\end{array}$ \\
\hline Estrutura de mercado & $\begin{array}{l}\text { Propôs criação do Sistema Nacional de } \\
\text { Correios }\end{array}$ & $\begin{array}{l}\text { Não alteraram estrutura do mercado } \\
\text { postal }\end{array}$ \\
\hline $\begin{array}{l}\text { Relação entre empresas no mercado } \\
\text { postal }\end{array}$ & $\begin{array}{l}\text { Competição entre operadores públicos } \\
\text { e privados no Sistema Nacional de Cor- } \\
\text { reios }\end{array}$ & $\begin{array}{l}\text { Competição somente nos segmentos } \\
\text { de mercado ausentes de monopólio. } \\
\text { Empresas ainda são proibidas de atuar } \\
\text { onde há reserva de mercado }\end{array}$ \\
\hline Agência reguladora & Propôs criação de agência reguladora & Regulação estatal \\
\hline $\begin{array}{l}\text { Arranjo institucional e organizacional da } \\
\text { ECT }\end{array}$ & $\begin{array}{l}\text { Pretendia transformar a ECT em socie- } \\
\text { dade de economia mista, com criação } \\
\text { de subsidiárias }\end{array}$ & $\begin{array}{l}\text { Transformaram a ECT em empresa públi- } \\
\text { ca com capital fechado e integralmente } \\
\text { da União, com estrutura e diretrizes das } \\
\text { sociedades anônimas. Permitida consti- } \\
\text { tuição ou aquisição de subsidiárias }\end{array}$ \\
\hline Banco Postal & $\begin{array}{l}\text { Previa a criação de banco próprio, mas } \\
\text { só conseguiu autorização para operar } \\
\text { por meio de parceria }\end{array}$ & $\begin{array}{l}\text { Aprovaram instrumento legal para cria- } \\
\text { ção de banco postal próprio }\end{array}$ \\
\hline Segmentos de mercado & $\begin{array}{l}\text { Previa a competição da empresa em to- } \\
\text { dos os segmentos do mercado postal }\end{array}$ & $\begin{array}{l}\text { Aprovaram lei para diversificar atuação } \\
\text { de mercado da ECT, como em serviços } \\
\text { de logística integrada }\end{array}$ \\
\hline Foco de mercado & Mercado nacional & $\begin{array}{l}\text { Possibilidade de atuação internacional, } \\
\text { principalmente no Mercosul }\end{array}$ \\
\hline
\end{tabular}

Fonte: Elaboração própria.

Verifica-se que durante o governo de Fernando Henrique Cardoso emergiram os principais pontos que integraram a pauta de discussões no setor postal nos anos seguintes. Dentre eles, a nova Lei Postal sintetizava o arranjo institucional proposto por aquele governo para o setor. A proposta previa a liberalização do mercado postal brasileiro com a eliminação gradual do monopólio da ECT e, em seu lugar, a criação do Sistema Nacional de Correios. A regulação do setor ficaria a cargo de uma agência reguladora responsável pela fiscalização e por garantir o cumprimento das normas que seriam estabelecidas. 
O presidente Luiz Inácio Lula da Silva descontinuou a tramitação do projeto da nova Lei Postal e manteve o monopólio para o segmento de cartas e mensagens, restringindo a competição aos nichos de mercado previstos na Lei ํㅜ 6.538, de 1978, o que não foi alterado pelo governo Dilma Rousseff. Ao mesmo tempo, a regulação do mercado continuou a ser exercida diretamente pelo governo. A ECT, assim, continuou a operar com a estrutura de mercado criada durante a ditadura militar.

Entre 1994 e 2011, as discussões sobre a reestruturação organizacional da ECT foram intensas. O governo de Fernando Henrique propunha a transformação da ECT em uma sociedade de economia mista, que pudesse constituir subsidiárias. Os governos Lula e Dilma Rousseff mantiveram a ECT como empresa pública com capital pertencente à União, mas incorporaram à estrutura organizacional da empresa instâncias de governança e administração adotadas por sociedades anônimas, além da possibilidade de a estatal possuir subsidiárias ou adquirir empresas já existentes.

Em termos de mercado, o governo FHC adotou medidas que foram continuadas e aprofundadas nos governos seguintes. É o que se observa na segmentação de mercado, em que as estratégias de todos os governos foram para incrementar a participação em diversos segmentos de mercado. Para isso, a reestruturação ocorrida com a promulgação da Lei no 12.490 , de 2011, institucionalizou a participação da empresa em nichos de mercado não previstos na legislação, como a logística integrada, assim como incorporou a estratégia do governo FHC que previa a inclusão das tecnologias da informação aos segmentos de mercado e à rede de serviços da empresa. Nesse mesmo sentido, o banco postal estava previsto pelo governo FHC, tendo funcionado com base na portaria criada pelo ex-presidente - frágil estratégia legal para funcionamento do banco ante a derrota da "nova Lei Postal". Com a reestruturação da ECT no governo Dilma Rousseff, a ECT agora dispõe de respaldo legal para constituir um banco próprio.

Do ponto de vista das estratégias políticas para o setor postal, portanto, há uma diferença entre os blocos políticos que ocuparam o governo federal no período. Observa-se que o projeto do governo FHC visava modernizar a ECT prevendo a competição no setor postal a partir da liberalização de mercado. Assim, as ações políticas desse governo estavam alinhadas ao projeto neoliberal. Durante o governo Lula e os primeiros anos do governo Dilma Rousseff, as propostas e as mudanças na corporatização dos Correios visavam ampliar a atuação de mercado e a inserção internacional da estatal. Assim, enquanto naquele governo havia a previsão de redução do papel do Estado e, por conseguinte, dos Correios, a partir de 2002 se observa o governo do PT atuando em prol do fortalecimento institucional e mercadológico da empresa, prevendo inclusive a sua internacionalização. São duas perspectivas de mercado, portanto, distintas.

As principais divergências sobre os rumos do setor entre os dois blocos políticos que governaram o país no período - PSDB e PT — estiveram, sobretudo, na estrutura de mercado (monopólio versus liberalização) e suas consequências organizacionais.

Diante desses elementos, constata-se que, do ponto de vista das estratégias políticas para o setor postal, os blocos políticos que ocuparam o governo federal entre 1994 e 2011 atu- 
aram de forma distinta. Tal diferença, contudo, não impediu a continuidade das estratégicas de modernização e corporatização da ECT no período.

\section{Referências}

ABVAKABO: we underestimated the consequences of postal liberalisation, UniGlobalunion, Read News, 7 maio 2011. Disponível em: <www.uniglobalunion.org/news/abvakabo-we-underestimatedconsequences-postal-liberalisation $>$. Acesso em: 6 out. 2011.

ABRUCIO, Fernando L. Trajetória recente da gestão pública brasileira: um balanço crítico e a renovação da agenda de reformas. Rev. Adm. Pública, Rio de Janeiro, v. 41, n. spe, p. 67-86, 2007.

A SEGUNDA revolução dos Correios, CEP BRASL, n. 1, jun. 1999.

ANDERLONI, Luisa; PILLEY, Odile. Changing context for postal systems in Europe. In: RUOZI, Roberto; ANDERLONI, Luisa. (Org.). Modernization and Privatization of Postal Systems in Europe. Berlin; Heidelberg: Springer, 2002.

ANDERSON, Perry. Balanço do neoliberalismo. In: SADER, Emir; GENTILI, Pablo (Org.). Pós-neoliberalismo: as políticas sociais e o Estado democrático. Rio de Janeiro: Paz e Terra, 1995. p. 9-23.

ANTUNES, Ricardo. A desertificação neoliberal: Collor, FHC, Lula. Campinas: Autores Associados, 2004.

ANTUNES, Ricardo. Adeus ao trabalho? Ensaios sobre as metamorfoses e a centralidade do mundo do trabalho. 7. ed. rev. ampl. São Paulo: Cortez; Unicamp, 2000.

ANTUNES, Ricardo. Os Sentidos do trabalho: ensaio sobre a afirmação e a negação do trabalho. São Paulo: Boitempo, 1999.

BARDIN, Laurence. Análise de conteúdo. Lisboa: Edições 70; LDA, 2009.

BARROS NETO, João P. Administração pública no Brasil: uma breve história dos Correios. São Paulo: Annablume, 2004.

BAYMA, Israel. Estudo técnico sobre serviços postais. Brasília: Assessoria Técnica do Partido dos Trabalhadores, 1999.

BIANCHI, Egydio. Correios e Privatização, Folha de S.Paulo, São Paulo, 20 maio 1999a. Tendências/ Debate, Caderno Opinião, p. 3.

BIANCHI, Egydio. Nem monopólio, nem privatização. Folha de S.Paulo, 6 ago. 1999b. Tendências/ Debates, Caderno Opinião 1, p. 3.

BOITO JR, Armando. A burguesia no governo Lula. Crítica marxista, São Paulo, n. 21, p. 52-77, 2005.

BOVO, Cassiano. Os Correios no Brasil e a organização racional do trabalho. São Paulo: Annablume, 1997. 
BRANDT, Torsten. Liberalisation, privatisation and regulation of postal services in Europe. European Comission's: Paper for PIQUE Project, 2007. Disponível em: <www.boeckler.de/pdf/wsi_pj_piq_ post_europe.pdf>. Acesso em: 5 set. 2011.

BRASIL. Balanço de governo. Estatais - Correios, 2010. Disponível em: <www.balancodegoverno. presidencia.gov.br/materiais-das-estatais/documentos/CORREIOS.pdf > . Acesso em: 3 jan. 2011.

BRASIL. Ministério das Comunicações. Programa de aceleração e ampliação do Sistema de Telecomunicações e do Sistema Postal — PASTE. Brasília, 1997.

BRASIL. Ministério das Comunicações. Sumário executivo. Brasília, 1998.

BRASIL. Ministério das Relações Exteriores. As transformações no setor de telecomunicações. Textos do Brasil, n. 3, 1996. Disponível em: <www.dc.mre.gov.br/imagens-e-textos/revista3-mat1.pdf> . Acesso em: 10 abr. 2011.

BRASIL. Relatório Final Grupo de Trabalho Interministerial — Correios. Brasília, 2009.

CARVALHO, Frederico A.; LEITE, Valdecy F. Adoção do franchising pelos Correios do Brasil: uma análise à luz da literatura. Rev. Adm. Pública, Rio de Janeiro, v. 30, n. 2, p. 167-186, mar./abr. 1996.

CANON, Michael. A nova Lei Postal. Folha de S.Paulo, São Paulo, 20 ago. 1999. Tendências/Debates, Caderno Opinião 1, p. 3.

CASTEL, Robert. As metamorfoses da questão social. Petrópolis: Vozes, 1999.

CASTELLS, Manuel. A sociedade em rede. A era da informação: economia, sociedade e cultura. São Paulo: Paz e Terra, 2005.

CONTRA o monopólio. Folha de S.Paulo, São Paulo, 20 out. 1999. Coluna Painel, Caderno Dinheiro, p. 2.

CREW, Michael; KLEINDORFER, Paul (Org.). Regulatory and economic challenges in the postal and delivery sector. Nova York: Springer Science, 2005.

FILGUEIRAS, Luiz A. M.; GONÇALVES, Reinaldo. A economia política do governo Lula. Rio de Janeiro: Contraponto, 2007.

HARVEY, David. Breve historia del neoliberalismo. Madri: Ediciones Akal, 2007.

HORST, Mark. Regulatory and economic challenges in the postal and delivery sector: a small step in weights, a giant leap for the market. In: CREW, Michael; KLEINDORFER, Paul R. (Org.). Regulatory and economic challenges in the postal and delivery sector. Nova York: Springer Science, 2005. p. 317-331.

LEAVEY, Thomas E. Introductory statement. In: RANGANATHAN, Kumar; DEY, Rohini. Redirecting mail: postal sector reform. Washington DC, 1996. Disponível em: <www-wds.worldbank.org/external/default/WDSContentServer/WDSP/IB/2000/09/15/000094946_00090105464250/Rendered/ PDF/multi_page.pdf>. Acesso em: 5 set. 2012.

MORAES, Roque. Análise de conteúdo. Revista Educação, Porto Alegre, v. 22, n. 37, p. 7-32, 1999. 
MOZZATO, Anelise R.; GRZYBOVSKI, Denize. Análise de conteúdo como técnica de análise de dados qualitativos no campo da administração: potencial e desafios. Revista de Administração Contemporânea, v. 15, n. 4, p. 731-747, jul./ago. 2011.

NASSIF, Luís. A nova Lei Postal, Folha de S.Paulo, São Paulo, 11 set. 1999. Caderno Dinheiro 2, p. 3. OCDE. Organização para Cooperação e Desenvolvimento Econômico. Promoting competition in postal services. Paris: Policy Roundtable, 1999.

PAVONI JÚNIOR, Gilberto; VASQUES, Eduardo. Embrulho do Barulho. Negócios e TI, 14 nov. 2001. Disponível em: <www.binegociosetibi.jex.com.br/seguranca/embrulho+do+barulho>. Acesso em: 17 out. 2011.

PEREIRA, Luiz Carlos B.; SPINK, Peter. Reforma do Estado e administração pública gerencial. Rio de Janeiro: FGV Editora, 1998.

RANGANATHAN, Kumar; DEY, Rohini. Redirecting mail: postal sector reform. Washington DC, 1996. Disponível em: <www-wds.worldbank.org/external/default/WDSContentServer/WDSP/IB/2000/0 9/15/000094946_00090105464250/Rendered/PDF/multi_page.pdf > . Acesso em: 17 jan. 2012.

SINGER, André. Raízes sociais e ideológicas do lulismo. Novos Estudos - Cebrap, São Paulo, n. 85, p. 83-102, 2009. Disponível em: <www.scielo.br/scielo.php?pid=S0101-33002009000300004\&script $=$ sci_arttext $>$. Acesso em: 25 abr. 2014.

TEIXEIRA, Tadeu G. Os correios em transformação: reestruturação, organização do trabalho e políticas de gestão do trabalho (1994-2011). Tese (doutorado em ciências sociais) — Instituto de Filosofia e Ciências Humanas, Universidade Estadual de Campinas, 2013.

VERGARA, Sylvia C.; CAVALCANTI, Celso O. B. A. ECT busca novos caminhos: de 1984 aos nossos dias. Rev. Adm. Pública, Rio de Janeiro, v. 29, n. 4, p. 239-259, 1995.

Tadeu Gomes Teixeira é doutor em ciências sociais pela Universidade Estadual de Campinas (Unicamp) e professor da Universidade Federal do Maranhão (Ufma).E-mail: tagote@gmail.com. 